\title{
Urdimento
}

Revista de Estudos em Artes Cênicas

E-ISSN: 2358.6958

\section{Artista-educa-dor: A somatopolítica neoliberal e a crise da sensibilidade do corpo ocidental}

Danilo Patzdorf

\section{Para citar este artigo:}

PATZDORF, Danilo. Artista-educa-dor: A somatopolítica neoliberal e a crise da sensibilidade do corpo ocidental.

Urdimento, Florianópolis, v. 1, n. 40, mar./abr. 2021.

do) DOI: http:/dx.doi.org/10.5965/1414573101402021e0101

Este artigo passou pelo Plagiarism Detection Software | iThenticate 
Artista-educa-dor:

A somatopolítica neoliberal e a crise da sensibilidade do corpo ocidental

\title{
Resumo
}

Danilo Patzdorf 1

O objetivo deste artigo é reconhecer o crescente cruzamento entre arte, saúde e espiritualidade realizado por diferentes artistas do corpo em seus projetos artístico-pedagógicos, avaliando-se de que maneira tais vivências podem interferir na crise da sensibilidade enfrentada pelo corpo ocidental. Para tanto, são descritos alguns dos mecanismos de controle e exploração articulados pela somatopolítica neoliberal, apresentando-se o artista-educador como a figura apropriada para oferecer experiências capazes de expressar e transformar os novos modos compulsórios de sofrer. Conclui-se com uma revisão dos possíveis significados para a palavra cura, frequentemente utilizada nestes contextos.

Palavras-chave: Corpo. Neoliberalismo. Arte. Educação. Cura.

Artist-educator:

Neoliberal somatopolitics and the sensitivity crisis of the western body

\begin{abstract}
The objective of this article is to acknowledge the growing intersection between art, health and spirituality that many body artists carry out in their artistic-pedagogical projects, assessing how such experiences can impact the crisis of sensitivity the western body faces. To this end, some of the control and exploration mechanisms that neoliberal somatopolitics articulate are described, presenting the artist-educator as the appropriate figure to offer experiences capable of expressing and transforming the new compulsory ways of suffering. It concludes with a review of the possible meanings for the word cure (or healing), often used in these contexts.
\end{abstract}

Keyword: Body. Neoliberalism. Art. Education. Healing.

Artista do corpo, arte-educador, pesquisador e professor de yoga. Autor do livro Sobre aquilo que um dia chamaram corpo: corporalidade nas ambiências digitais (ed. Letramento, 2019), está concluindo um doutorado sobre corpo, neoliberalismo e autocuidado em arte-educação (ECA-USP). Mestre em comunicação (ECA-USP). Licenciado em artes visuais (ECA-USP). danilo patzdorf@hotmail.com

(9) http://lattes.cnpq.br/4609796353996635 (iD) https://orcid.org/0000-0002-2538-8828 
Artista-educa-dolor:

La somatopolítica neoliberal y la crisis de la sensibilidad del cuerpo occidental

\section{Resumen}

El objetivo de este artículo es reconocer la creciente intersección entre arte, salud y espiritualidad que llevan a cabo diferentes artistas del cuerpo en sus proyectos artístico-pedagógicos, evaluando cómo tales experiencias pueden interferir en la crisis de la sensibilidad que enfrenta el cuerpo occidental. Para ello, describiremos algunos de los mecanismos de control y explotación articulados por la somatopolítica neoliberal, presentando al artista-educadolor como la figura adecuada para ofrecer experiencias capaces de expresar y transformar las nuevas formas compulsivas del sufrimiento. Concluiremos con una revisión de los posibles significados de la palabra cura, que, a menudo, es utilizada en estos contextos.

Palabras clave: Cuerpo. Neoliberalismo. Arte. Educación. Cura. 
Por que é que artistas do corpo, da performance, do movimento e da cena estão cada vez mais se apropriando de intervenções terapêuticas e espirituais, até então reservadas aos profissionais da saúde e às autoridades religiosas? Por que é que tais artistas, acostumados com o espaço do palco, da galeria, da rua ou do vídeo, estão preferindo compartilhar seus procedimentos de investigação e criação no formato de aulas, cursos, vivências ou encontros (presenciais e on-line), em vez de apresentações e exposições? Que tipo de cura as experiências artísticopedagógicas podem operar no corpo individual e social? Se a figura do artistaeduca-dor, aqui proposta, for entendida como aquele que educa a dor, em que aspecto a arte-educação pode nos ajudar a perceber, lidar, narrar, enfrentar ou, inclusive, tratar as dores, os sofrimentos e os mal-estares específicos da nossa época?

Perante tais perguntas, este artigo é uma tentativa de evidenciar e reconhecer o crescente cruzamento entre o campo da arte (especialmente as linguagens que envolvem o corpo do artista, como dança, teatro, performance, happening etc.) com o campo da saúde (psicoterapia, massoterapia, fisioterapia, neurologia, práticas integrativas, educação física etc.) e da espiritualidade (yoga, chi kung, budismo, taoísmo, umbanda, candomblé, xamanismo etc.), cruzamento esse operado por artistas brasileiras e brasileiros que estão preferindo o espaço pedagógico ao invés do espaço expositivo para partilhar suas ações, invenções e intervenções.

Aparentemente, mesmo os recursos participativos/interativos/colaborativos da chamada "arte relacional" (cf. Borriaud, 2009), caros à performance e à cena das últimas décadas, estão se tornando insuficientes ${ }^{2}$ para efetuarmos um encontro relevante com o público, com o espectador, com o transeunte ou com o visitante, daí o recurso artístico-pedagógico sobrevir como uma opção para, mais

\footnotetext{
${ }^{2}$ [...] uma sociedade democrática em pleno funcionamento não é aquela em que todo o antagonismo desaparece, mas aquela em que novas fronteiras políticas são constantemente traçadas e colocadas em debate - em outras palavras, uma sociedade democrática é aquela em que as relações de conflito são sustentadas e não apagadas. Sem antagonismo existe apenas um consenso imposto por uma ordem autoritária - uma total supressão do debate e da discussão, que é desfavorável à democracia. [...]. Debruçome sobre essa teoria para sugerir que as relações estabelecidas pela estética relacional não são intrinsecamente democráticas, como sugere Bourriaud, já que elas permanecem confortavelmente dentro de um ideal de subjetividade como um todo e de uma comunidade como união imanente (Bishop, 2012, p. 121-122)
} 
uma vez, tentar furar as fronteiras entre arte e vida que se interpõem reiteradamente entre o fazer artístico e a sociedade.

Outra recalcitrante fronteira que parece se adensar continuamente é aquela entre indivíduo e sociedade, cuja operação consiste em fraturar o convívio social, seja em espaços públicos ou privados, turvando afetos e sentimentos como empatia, simpatia e alteridade. Consequência esta, direta ou indireta, da crescente urbanização e digitalização do cotidiano que, embora facilitem a possibilidade de ocorrerem encontros presenciais e virtuais, constituem-se fundamentalmente como espaços de controle. Isto é, a sociabilidade travada nas ruas e nas telas geralmente descrevem um percurso mais ou menos previsto pelas leis e pelos algoritmos, obedecendo ao comportamento e à temporalidade estabelecidos pela estrutura da cidade e pelas interfaces dos dispositivos digitais.

Assim, o espaço das relações habituais é o que se encontra mais duramente atingido pela reificação geral. Se quiser escapar ao domínio do previsível, a relação humana - simbolizada ou substituída por mercadorias, sinalizada por logomarcas - precisa assumir formas extremas ou clandestinas, uma vez que o vínculo social se tornou um produto padronizado (Borriaud, 2009, p.12).

É neste cenário que a arte relacional se propõe “[...] efetuar ligações modestas, abrir algumas passagens obstruídas, pôr em contato níveis de realidade apartados" (Borriaud, 2009, p. 11). Entretanto, apesar das investidas criativas da arte para tentar suprir a ausência de políticas sociais que restabeleçam os laços e direitos continuamente suprimidos pela governamentalidade neoliberal, tais operações ocorrem no espaço protegido e consensual da galeria e do museu. Por isso,

É preciso examinar, em outros termos, se na tentativa de suprir a ausência de políticas sociais, o que teríamos nos espaços de arte relacional ou radicante é uma sociabilidade glamourizada, fictícia porque factícia, um espaço polido e desdramatizado, um simulacro, enfim, da sociabilidade dita real porque fundada na imprevisibilidade e nos conflitos, tal como se manifesta ordinariamente no espaço público (Fabrinni, 2014, p. 56, grifos nossos).

Se nossos dispositivos performáticos e cênicos estão falhando na "tentativa 
de suprir a ausência de políticas sociais", ao menos no contexto institucional da arte, talvez isso ocorra porque os mecanismos de controle, exploração e espoliação dos nossos corpos e das nossas subjetividades estão se aprimorando, cada vez mais rapidamente, a ponto de se tornarem imperceptíveis e, portanto, incapturáveis, obsolescendo prematuramente as tentativas poéticas de intervir nos nossos modos de perceber, viver e conviver. Dificuldade essa, ademais, agravada pelo avanço do neoliberalismo e a consequente ascensão da política antidemocrática no ocidente (cf. Brown, 2019), cujo pressuposto, justamente, é o retrocesso ou o ataque às políticas sociais estabelecidas. Por isso, não só a arte, mas também a sociologia e a psicologia estão fracassando na "tentativa de suprir a ausência de políticas sociais". Não por falta de esforço, mas porque, enquanto estamos desenvolvendo proposições estéticas, diagnósticos sociológicos ou programas psicoterapêuticos para tentar intervir nas fraturas sociais/relacionais da nossa época, as estratégias de sujeição social, corporal e psíquica já se instalaram em dimensões ainda mais íntimas da nossa existência.

Ao passo que liberais clássicos [...] consideravam que o sofrimento, seja do trabalhador, seja do cidadão, é um problema que atrapalha a produção e cria obstáculos para o desenvolvimento [...], a forma de vida neoliberal descobriu que se pode extrair mais produção e mais gozo do próprio sofrimento (Dunker, 2017, p. 284, grifos nossos).

Ou seja, o sofrimento crônico que experimentamos em diferentes intensidades na escala individual e coletiva não é um efeito colateral indesejado da contínua expropriação capitalista, mas sim um projeto. Nesse sentido, os distúrbios psíquicos (depressão, ansiedade, crise de pânico, insônia, entre outros) que estamos desenvolvendo globalmente, no início do século XXI, são programados pelas políticas do sofrimento cotidiano. Isto é, o neoliberalismo pressupõe um corpo que não aguenta mais (cf. Lapoujade, 2002), pressupõe uma sociedade cansada (cf. Han, 2017), pressupõe um corpo esgotado (cf. Deleuze, 2010).

Partindo das contribuições de Paul B. Preciado (2018), chamaremos esse programa político de controle e servidão dos corpos e subjetividades de 
somatopolitica neoliberal, operando, para tanto, conforme veremos adiante: (1) o sedentarismo compulsório, (2) a privação sensorial e (3) a supremacia da extroversão. É assim que a constante captura da vitalidade, da expressividade, da coletividade e da liberdade dos nossos corpos têm nos lançado numa crise generalizada, para que a desorientação, o esgotamento, o disciplinamento e o desencantamento perante a vida mantenham os mecanismos de controle e exploração em pleno funcionamento.

A crise é permanente, mudando apenas de intensidade e de nome. A governamentalidade liberal se exerce passando da crise econômica para a crise climática, para a crise demográfica, para a crise energética, para a crise alimentar etc. Mudando de nome, troca-se apenas de medo. A crise e o medo constituem o horizonte insuperável da governamentalidade capitalista neoliberal. Nós não sairemos da crise (na melhor das hipóteses, nós mudaremos de intensidade) simplesmente porque ela é a modalidade de governo do capitalismo contemporâneo (Lazzarato, 2017, p. 11, grifo nosso).

Se considerarmos que a crise que estamos vivendo não é somente econômica, política, ambiental, habitacional, sanitária e educacional, mas também uma crise da sensibilidade, então a arte-educação se apresenta como um potente recurso de experimentação corporal e subjetiva capaz de expressar e transformar os desequilíbrios físico, mental, emocional e "energéticos" programados pela somatopolítica neoliberal.

Neste contexto, resta aos artistas a árdua tarefa de deslindar o invisível para nos auxiliar a escavar, confrontar e reinventar a própria intimidade, antes mesmo dos profissionais de saúde ou das autoridades religiosas, pois nosso sofrimento, mais do que nunca, está com suas raízes fincadas não somente na fisiologia (saúde) ou na metafísica (religião), mas no conjunto de sensorialidades e gestualidades (estética) que constituem nosso corpo ocidental, urbano, industrializado e digitalizado.

Isso sugere que talvez tenham sido as artes e a política, antes das ciências psicológicas, que captaram essa deriva e transformação de

${ }^{3}$ Somato deriva do grego soma que exprime a ideia de corpo vivo ou morto. Somatopolítica é um termo que tomamos emprestado de Preciado (2018) que o utiliza para se referir à noção de tecnologia política do corpo ou somatopoder desenvolvida por Foucault (2013). 
nossos modos compulsórios de sofrer e de exprimir nosso sofrimento, bem como elas que nos provêm novas formas e linguagens para novas maneiras de sofrer (Dunker, 2017, pp. 285-286, grifos nossos).

Dado o expressivo aumento dos casos mundiais de suicídio (a cada quarenta segundos, uma pessoa se suicida no mundo), ${ }^{4}$ prognosticada a depressão como a doença mais incapacitante da década de $2020^{5}$ e ocupando o Brasil o topo do ranking mundial dos países com maior número de casos de ansiedade, 6 “[...] parece evidente que assistimos a uma degradação irreversível dos operadores tradicionais de regulação social” (Guattari, 2012, p. 30). Vale questionarmos, portanto, se nossos atuais recursos terapêuticos e religiosos seriam capazes, por si sós, de transformarem "nossos modos compulsórios de sofrer e de exprimir nosso sofrimento", na atual conjuntura. É deste modo que invocamos o neologismo artista-educa-dor - mais do que os "[...] profissionais 'psi', sempre assombrados por um ideal caduco de cientificidade" (Guattari, 2012, p. 16), e mais do que as autoridades religiosas, sempre assombradas por doutrinas imutáveis - como a figura apta a nos auxiliar, conforme veremos, na reinvenção dos corpos e subjetividades destroçados pelas três grandes fases do capitalismo (colonização, industrialização e financeirização).

Explícita ou implicitamente, ainda que haja um certo desprestígio silencioso sobre o profissional da arte-educação no espaço institucional e fora dele, são vários os projetos de artistas do Brasil que atualmente operam esse cruzamento arte-saúde-espiritualidade no contexto artístico-pedagógico. O que há de notável nesse dado é que tais cursos e aulas não se configuram apenas como uma "abertura" do processo criativo (geralmente exigidos por editais de financiamento público ou privado, enquanto uma contrapartida social para a verba investida), mas o seu ápice. Em outras palavras, o encontro artístico-pedagógico deixa de ser secundário no processo criativo de tais artistas para se transformar na própria

${ }^{4}$ Segundo os dados oficiais da Organização Mundial da Saúde, disponível em https://www.who.int/healthtopics/suicide\#tab=tab_2, Acesso em: 17 dez. 2020.

${ }^{5}$ Disponível em https://www.who.int/news-room/fact-sheets/detail/depression, Acesso em: 17 dez. 2020.

${ }^{6}$ Disponível em:

https://www.who.int/mental health/management/depression/prevalence global health_estimates/en/,

Acesso em: 17 dez. 2020. 
obra ou no seu "produto final".

Assim, sob o formato de aulas, cursos, vivências ou encontros (presenciais e on-line), tais artistas do corpo, da performance, do movimento e da cena propõem uma relação menos acelerada e menos impessoal do que aquelas possíveis no palco, na galeria, na rua ou no vídeo. De maneira geral, partindo de diferentes referenciais artísticos, pedagógicos, terapêuticos ou espirituais, esses projetos oferecem um conjunto de experiências e ações para serem realizadas pelos alunos/participantes, estimulando processos de autoconhecimento e autocuidado capazes de restabelecer, ainda que temporariamente, os vínculos com a vitalidade, a expressividade, a coletividade e a liberdade capturadas pela somatopolítica neoliberal.

Mas, como comentar esse acontecimento sem se apoiar na teoria da arte experimental dos anos 1960-1970 e sem se apoiar na teoria da arte relacional dos anos 1990-2000? Assim, sustentaremos como hipótese principal ${ }^{7}$ deste artigo que o crescente cruzamento arte-saúde-espiritualidade operado por artistas do corpo se deve à urgência com que outros "saberes somáticos" ou "epistemologias corporais" precisam ser reconhecidos e praticados para que consigamos imaginar e propor novas estratégias de insurreição contra os mecanismos somatopolíticos de controle e exploração mais contemporâneos.

Para tanto, não basta que espectadores assistam a, participem de ou se relacionem com o resultado de uma determinada criação artística (seja cena, performance, espetáculo etc.). É necessário que vivenciem experiências capazes de burlar, confrontar, requalificar ou desmontar a sensorialidade conformada pelo corpo ocidental, vislumbrando novos modos de sentir para além daqueles

\footnotetext{
Há outras hipóteses possíveis para explicar esse crescente cruzamento arte-saúde-espiritualidade realizado por artistas que, por limitações de espaço, não serão aqui desenvolvidas. Brevemente, por exemplo, podemos considerar as seguintes hipóteses: 1) econômica: dados os cortes e diminuições nos patrocínios públicos e privados à arte, artistas estão recorrendo ao formato da aula porque é mais fácil ganhar dinheiro com cursos do que com apresentações; 2) filosófica: com a mutação no estatuto da mercadoria operada pelo capitalismo pós-industrial que, de objeto físico comprável se transforma em uma experiência (turismo, gastronomia, moda, indústria audiovisual, drogas legais e ilegais etc.), ocorre também uma mutação no estatuto do objeto artístico que, enquanto mercadoria, deve se adaptar à nova lógica de produção-consumo para continuar circulando/vendendo; 3) soteriológica: dada a supremacia da cultura visual (sensorial) sobre a cultura escrita (mental), a figura do artista se aproxima cada vez mais da condição de um xamã (que enuncia a realidade invisível através do contato espiritual) do que aquela do intelectual (que enuncia a realidade invisível através de elaborações racionais); entre outras.
} 
estabelecidos.

Dos vários projetos de artistas brasileiras e brasileiros que estão cruzando arte-saúde-espiritualidade, mencionamos apenas alguns daqueles com os quais pudemos ter contato direto e que se identificaram, minimamente, com as hipóteses aqui levantadas. Agrupamos tais projetos porque, cada um à sua maneira, desenvolvem metodologias de ensino e criação singulares que nos auxiliam a perceber, narrar, enfrentar ou inclusive tratar as dores, os sofrimentos e os mal-estares decorrentes dos modos de viver capitalistas. Assim, ao cruzarem distintas perspectivas artísticas, pedagógicas e terapêuticas, tais projetos instauram uma espécie de laboratório coletivo de criação somato-político-ecoético-estético, no qual se torna possível recriarmos, ao menos poeticamente, a relação com nossos próprios corpos.

São eles: "Práticas de Vitalidade", de Bárbara Malavoglia (@barbara_malavoglia); “Estéticas macumbeiras na Clínica da Efemeridade”, de Castiel Vitorino (@castielvitorino); “Cerimônias para quietude”, de Danielli Mendes (@danilli_mendes); “Yoga para corpos urbanos”, "Massageaço”, “Oração corporal” e "Corpo, movimento e cura”, de Danilo Patzdorf (@danilopatzdorf); "Clínica somático-performática”, de Diogo Rezende (@atletismo.afetivo); “Práticas de encantamento da matéria”, de Elisabete Finger (@elisabetefinger); “Escola do reparar”, dirigida por Fernanda Eugênio (@andlab.reparar); "Dança intuitiva”, de Inaê Moreira (@dancaintuitiva); “Tai Chi e Kung Fu como matriz do movimento”, de Mariana Molinos (@marianamolinos); “Corpo-antena”, de Patrícia Bergantin (@patbergantin); “Pélvika”, de Thiane Nascimento (@pelvika); entre muitos outros.

Dito isso, o objetivo deste artigo não é mapear tais projetos e artistas para discuti-los individualmente, mas fornecer alguns recursos conceituais para que consigamos localizar e compreender de que maneira o cruzamento arte-saúdeespiritualidade pode nos auxiliar a revelar e transformar os processos somatopolíticos que conformam os corpos na contemporaneidade. Com isso, acreditamos amparar e enriquecer nossa prática artístico-pedagógica, bem como

${ }^{8}$ Projetos citados em ordem alfabética de acordo com o primeiro nome de cada artista proponente, seguidos do endereço eletrônico das suas respectivas páginas de Instagram. 
o debate acadêmico em torno dela. Para tanto, passemos agora à investigação das forças somatopolíticas neoliberais e à crise da sensibilidade do corpo ocidental.

\section{A somatopolítica neoliberal: \\ desencantamento, disciplinamento e esgotamento}

A história do corpo ocidental ${ }^{9}$ é inseparável da história do capitalismo e suas tecnologias. Não é possível compreender o corpo, no século XXI, sem compreender as injunções técnicas, políticas e subjetivas que o constituíram ao longo das três grandes fases do capitalismo: o regime soberano da monarquia escravocrata do capitalismo agrícola (colonização, relação senhor-escravo), o regime disciplinar da burguesia liberal-democrática do capitalismo industrial (industrialização, relação patrão-proletário) e o regime de controle das oligarquias transnacionais do capitalismo neoliberal (financeirização, relação mercado-microempreendedor). ${ }^{10}$

Cada uma dessas fases articulam diferentes estratégias somatopolíticas para justificar e facilitar a sujeição (voluntária ou involuntária) aos mecanismos de controle e exploração das nossas existências. ${ }^{11}$ Ou seja, para cada época, não faltaram justificativas morais, econômicas, técnicas e até metafísicas para formar, conformar e naturalizar a condição do corpo explorado do escravizado (corpos racializados negros ou indígenas, não-brancos), do proletariado (inicialmente corpos europeus pobres, não-burgueses) e do "precariado" (trabalhadores informais, terceirizados, temporários, vulneráveis, precarizados, com pouca ou nenhuma estabilidade, garantia ou direito assegurados). “Em outras palavras, hoje

${ }^{9}$ Conforme veremos adiante, corpo ocidental é um termo propositalmente impreciso para tentar designar o conjunto imensamente diverso de corpos sujeitados à fase globalizada do capitalismo, isto é, podemos entender por corpo ocidental essa corporalidade genérica que, apesar das especificidades (regionais, culturais ou fenotípicas) de cada povo, possui comportamentos, gestos e desejos mais ou menos parecidos, oferecendo, assim, um campo minimamente uniforme de atuação e expansão do capital neoliberal. Ou seja, embora este corpo derive da cultura dita ocidental, ele já se globalizou por todos os cantos.

10 Por limitações de espaço, neste artigo desenvolveremos apenas e brevemente as questões relativas à fase da financeirização, aqui debatidas sob o termo neoliberal.

11 "Esses três regimes de produção de corpos e subjetividades sexuais não deveriam ser entendidos como meros períodos históricos. O regime disciplinar não apaga as técnicas de soberania necropolítica. Da mesma forma, o regime farmacopornográfico não oblitera totalmente as técnicas biopolíticas disciplinares. Três técnicas diferentes e conflitantes de regime de poder estão justapostas e atuam no corpo produzindo nosso sujeito contemporâneo e nossa ficção somática" (Preciado, 2018, p. 85). 
é filosoficamente relevante realizar uma análise somatopolítica da economia mundial" (Preciado, 2018, p. 26).

Se “[...] a primeira máquina desenvolvida pelo capitalismo foi o corpo humano e não a máquina a vapor" (Federici, 2017, p. 268), então não podemos considerar nossos corpos, nossa aparência, nossos desejos, nossos afetos e nossos gestos como manifestações naturais do acaso ou do destino porque, por detrás de cada pensamento, sentimento e movimento, há um conjunto de poderes, discursos e costumes em ação e reprodução. Por isso, "[...] já não se trata de revelar a verdade oculta na natureza, e sim da necessidade de explicitar os processos culturais, políticos e tecnológicos por meio dos quais o corpo, enquanto artefato, adquire um status natural” (Preciado, 2018, p. 38). Todo esse esforço foi e continua sendo empreendido para que seja cada vez mais possível a alienação do corpo, isto é, que trabalhadores (terceirizados, assalariados ou escravizados) “[...] subordinem sua atividade a uma ordem externa, sobre a qual não têm controle e com a qual não podem se identificar" (Federici, 2017, p. 243).

No princípio do capitalismo, para que diferentes povos das Américas, da África e de países do Oriente se submetessem à escravidão imposta pelos colonizadores europeus - além do assassinato de dezenas de milhões de pessoas no maior genocídio registrado na história da humanidade -, foram organizadas estratégias filosóficas, religiosas, jurídicas, geográficas e científicas para desconectar o corpo do seu território, aniquilar seus saberes ancestrais, desmembrar as comunidades constituídas e desinvestir simbolicamente qualquer tipo de conexão com a natureza; processo esse que podemos chamar genericamente de desencantamento do corpo.

Isso significa que o corpo mecânico, o corpo-máquina, não poderia ter se convertido em modelo de comportamento social sem a destruição, por parte do Estado, de uma ampla gama de crenças pré-capitalistas, práticas e sujeitos sociais cuja existência contradizia a regulação do comportamento corporal prometido pela filosofia mecanicista (Federici, 2017, p. 257).

Com os corpos desencantados e expropriados, estava aberto o terreno para 
um outro processo que podemos chamar genericamente de disciplinamento do corpo, visando, daí em diante, produzir um comportamento padronizado, homogêneo e uniforme, fundamental para o funcionamento regular e repetitivo do novo tipo de produção industrial. Com a sociedade disciplinar, descrita por Foucault (2013), inicia-se, então, um esquadrinhamento detalhado do tempo e do espaço, instaurando uma vigilância generalizada que não só pune, mas prevê e neutraliza qualquer movimento desautorizado. Por meio de instituições, profissionais e leis, o regime soberano (fazer morrer e deixar viver) é paulatinamente substituído pela biopolítica (fazer viver e deixar morrer) que, em vez de espetacularizar a punição dos delinquentes em praça pública como forma de prevenir futuras desobediências através do medo, prefere fabricar massas de corpos dóceis. ${ }^{12}$

O momento histórico das disciplinas é o momento em que nasce uma arte do corpo humano, que visa não unicamente o aumento de suas habilidades, nem tampouco aprofundar sua sujeição, mas a formação de uma relação que no mesmo mecanismo o torna tanto mais obediente quanto é mais útil, e inversamente. Forma-se então uma política das coerções que são um trabalho sobre o corpo, uma manipulação calculada de seus elementos, de seus gestos, de seus comportamentos. o corpo humano entra numa maquinaria de poder que o esquadrinha, o desarticula e o recompõe. Uma "anatomia política", que é também igualmente uma "mecânica do poder", está nascendo; ela define como se pode ter domínio sobre o corpo dos outros, não simplesmente para que façam o que se quer, mas para que operem como se quer, com as técnicas, segundo a rapidez e a eficácia que se determina. A disciplina fabrica assim corpos submissos e exercitados, corpos "dóceis" (Foucault, 2013, p. 133, grifo nosso).

Mas se, até meados do século XIX, era mais ou menos possível observar externamente os mecanismos de controle agindo sobre os corpos, no século XX e XXI essas geringonças ortopédicas de controle se diluem progressivamente nos fluxos informativos das tecnologias digitais, oferecendo "[...] uma série de novas tecnologias do corpo (biotecnologia, cirurgia, endocrinologia, engenharia genética

\footnotetext{
12 No entanto, como nos relembra Federici, "[...] não foi pacificamente que os trabalhadores e artesãos expropriados aceitaram trabalhar por um salário. Na maior parte das vezes, se converteram em mendigos, em vagabundos e em criminosos. Seria necessário um longo processo para produzir mão de obra disciplinada. Durante os séculos XVI e XVII, o ódio contra o trabalho assalariado era tão intenso que muitos proletários preferiam arriscar-se a terminar na forca a se subordinarem às novas condições de trabalho" (Federici, 2017, p. 245).
} 
etc.) e de representação (fotografia, cinema, televisão, internet, videogame etc.) que se infiltram e penetram como nunca a vida cotidiana" (Preciado, 2018, p. 8485).

Para que fosse realizada a passagem de um capitalismo industrial (chão de fábrica), pautado na produção, consumo e acumulação de mercadorias materiais (carros, roupas, eletrodomésticos etc.), para um capitalismo pós-industrial (home office), pautado, sobretudo, na produção e circulação de mercadorias ditas imateriais $^{13}$ (informações, imagens, experiências etc.), o corpo foi tomado como a peça privilegiada desse jogo de esconder os mecanismos somatopolíticos deveras artificiais sob a rubrica natural. A instauração e manutenção da lógica neoliberal nas mais íntimas dimensões da vida e do cotidiano, em nível global, se deve justamente a esta "interiorização do corpo 'natural' e do corpo 'individuado'” (Lazzarato, 2017, p. 186).

Testemunhamos progressivamente a miniaturização, internalização e introversão reflexiva (movimento de torção para o interior, para o espaço considerado como íntimo e privado) dos mecanismos de controle e vigilância do regime sexopolítico disciplinador. Essas novas tecnologias suaves de microcontrole adotam a forma do corpo que controlam, transformam-se em corpo, até se tornarem inseparáveis e indistinguíveis dele, acabando como soma-tecno-subjetividades. O corpo já não habita os espaços disciplinadores: está habitado por eles. A estrutura orgânica e biomolecular do corpo é o último esconderijo desses sistemas biopolíticos de controle (Preciado, 2018, p. 86).

O trunfo da somatopolítica neoliberal se dá nessa in-corporação do poder, fazendo coincidir o desejar com o consumir. Não precisamos mais obedecer ao padre, ao general, ao pai, ao cientista, ao professor ou ao médico para produzirmos e consumirmos. Basta que obedeçamos ao próprio desejo para que automaticamente façamos o capital circular. No século XXI, em que as mercadorias são nossos corpos e afetos, saciar irrefletidamente nossos desejos significa efetuar o biocapitalismo.

\footnotetext{
13 "Claro que com isso não quero dizer que haja desaparecido o trabalho material, ao contrário, o trabalho pesado, duro, está terrivelmente presente, presente demais. Estou dizendo simplesmente que o trabalho material é cada vez mais modelado por técnicas científicas e modificações tecnológicas que comportam a transformação do trabalho, que se torna cada vez mais força de trabalho intelectual [e sexual, acrescentará Preciado], enquanto a informatização recolhe a mais-valia social de uma sociedade subsumida" (Negri, 2015, p. 62, grifo nosso).
} 
Quando guiamos nossas escolhas e ações a partir daquela manifestação aparentemente intrínseca - o desejo -, crendo assim honrar um princípio aparentemente pessoal e intransferível - porque essa sensação vem de "dentro" de mim, do "meu" "interior" -, no fundo, estamos cumprindo uma coreografia previamente definida e introjetada a ponto de parecer-nos autêntica, desde o desejo de comer um hambúrguer fast food produzido e entregue por trabalhadores precarizados, beber um refrigerante das maiores empresas poluidoras de plástico do mundo, adquirir o mais novo dispositivo digital fabricado por mão de obra análoga à escravidão, mas também o vício em redes sociais, pornografia, games e outros recursos audiovisuais psicotóxicos.

A desterritorialização capitalista opera sobre o desejo de modos que não são propriamente humanos, mas, sim, maquínicos. O desejo não é a expressão da subjetividade humana; ele emerge do agenciamento de fluxos humanos e não humanos, de uma multiplicidade de máquinas técnicas e sociais (Lazzarato, 2014, p. 49).

Não importa se material ou imaterial, orgânico ou inorgânico, pessoal ou impessoal, a nova lógica da produção-consumo do capitalismo farmacopornográfico consiste em mobilizar o "[...] complexo material e virtual que participa da indução de estados mentais e psicossomáticos de excitação, relaxamento e descarga" (Preciado, 2018, p. 42). O que há na raiz desses desejos de consumo cotidianos é a necessidade neuroendocrinológica de acionar as cadeias psicossomatoestimulantes, “[...] cujo princípio é reproduzir compulsivamente o ciclo excitação-frustração até atingir a destruição total dos ecossistemas" (Preciado, 2018, p. 295).

Uma das chaves do circuito produtivo excitação-frustração-excitação é o caráter toxicológico do prazer sexual. Quando falamos de uma economia farmacopornográfica, é preciso levar em conta o fato de que ambos os tentáculos (o fármaco e o pornô) exploram uma base somatopolítica comum: a dimensão toxicológica do prazer. O prazer (em sua capacidade de satisfação frustrante) da multidão é a última fonte de produção de riqueza (Preciado, 2018, p. 324).

Com a sensação de autoria e posse sobre esse desejo aparentemente 
individual, sentimo-nos mais livres ao saciar uma volição interna. Mas é justamente essa sensação de liberdade a principal arapuca do neoliberalismo: almejando exercer a própria liberdade, tropeçamos numa autoexploração que não necessita de nenhum algoz, patrão ou policial mandando e desmandando para que a produtividade e o consumo se multipliquem infinitamente.

A liberdade do capital se realiza por meio da liberdade individual. Dessa maneira, o individuo livre é rebaixado a órgão genital do capital. A liberdade individual concede ao capital uma subjetividade "automática", que o incita à reprodução ativa. [...] A liberdade individual, que atualmente assume uma forma excessiva, é nada mais nada menos do que o excesso do próprio capital (Han, 2018, p. 13, grifos nossos).

Perante o caráter "automático" com que reproduzimos ativamente a circulação do capital digital (evidente, por exemplo, na infinita disposição que temos para administrar diariamente nossas redes sociais, sendo o Brasil o terceiro país que mais utiliza o Instagram no mundo, ${ }^{14}$ gastando, em média, quase quatro horas por dia, ${ }^{15}$ garantindo, assim, que seu proprietário, Mark Zuckerberg, alcance o posto de terceiro homem mais bilionário do mundo), ${ }^{16}$ os termos servidão voluntária ou sujeição social soam insuficientes para descrever nossa atual subordinação. Ao que tudo indica, nossa atual obediência será mais bem descrita como uma servidão maquínica:

A servidão não opera através de repressão ou de ideologia [como no regime soberano ou disciplinar]. Ela emprega técnicas de modelização e de modulação que incidem sobre o que seria exatamente o "espírito da vida e da atividade humana". Ela assume o controle dos seres humanos "por dentro", no nível pré-pessoal (no nível pré-cognitivo e pré-verbal) e "por fora", no nível suprapessoal, ao atribuir a eles certos modos de percepção e sensibilidade e fabricar um inconsciente. A formatação exercida pela servidão maquínica intervém no funcionamento básico do comportamento perceptivo, sensitivo, afetivo, cognitivo e linguístico" (Lazzarato, 2014, p. 38, grifos do autor).

\footnotetext{
${ }^{14}$ Disponível em: https://www.digitalturbine.com/blog/brazil-the-app-economy-is-about-to-explode/. Acesso em: 04 jan. 2020.

15 Disponível em: https://agenciabrasil.ebc.com.br/en/geral/noticia/2020-01/brazil-ranks-third-app-usagetime. Acesso em: 04 jan. 2020.
}

${ }^{16}$ Disponível em: https://www.forbes.com/real-time-billionaires/\#7ed6167d3d78. Acesso em: 11 mar. 2021. 
Assim, agindo em instâncias pré-pessoais da nossa existência, a somatopolítica neoliberal dá continuidade à estratégia capitalista de acumulação por meio de trabalho não remunerado. Se o trabalho não remunerado foi/é extraído compulsoriamente dos corpos negros, racializados e não-brancos subalternizados pela ficção da raça (Mbembe, 2018) e extraído também do trabalho doméstico e sexual não remunerado realizado pelos corpos das mulheres (Federici, 2019), a implicação subjetiva e corporal que ora desenvolvemos com o neoliberalismo também the rende uma "[...] quantidade enorme de trabalho gratuito" (Lazzarato, 2014, p. 51).

Com a digitalização do cotidiano, qualquer gesto que se faça mediado por alguma tela está sujeito a ser convertido em trabalho; afinal, clicar é produzirconsumir. Assim, desaparece a fronteira entre trabalhar e descansar, transformando até mesmo nossos momentos de lazer, diversão ou prazer em entretenimento capitalizável: o brincar das crianças, a masturbação dos jovens, a reunião dos adultos. Deste modo, vivenciamos pouco a pouco a transição de um capitalismo negativo, proibitivo, coercitivo, austero, cinza para um capitalismo positivo, libertário, colorido, soft, hilário, excitante que, não obstante, dá continuidade à acumulação desigual por meio da exploração do próprio corpo como um dos principais "[...] objetos biopop da sociedade de consumo (Preciado, 2018, p. 34).

Superpondo-se ao ecocídio, ao genocídio e ao epistemicídio realizados pela colonização e pela industrialização, a nova ordem mundial imposta pela financeirização tende a fundir o capitalismo e o animismo, isto é, "à transformação dos seres humanos em coisas animadas, dados numéricos e códigos" (Mbembe, 2018, p. 19, grifo nosso), coisidade essa enfrentada desde sempre pelos corpos racializados escravizados na primeira fase do capitalismo colonial - destituídos de qualquer possibilidade de autodeterminação, tal qual um objeto - que agora tendem a se universalizar sobre qualquer corpo subalternizado pela somatopolítica neoliberal numa espécie de devir-negro do mundo (Mbembe, 2018, p. 20). Em outras palavras, a política de exploração e extermínio colonial continua viva e agora está se expandindo para além dos corpos negros/racializados para 
alcançar qualquer corpo subalternizado pelo neoliberalismo.17

É dessa constante autoexploração que emerge a sensação generalizada de esgotamento. Sobrepondo-se aos mecanismos de controle e exploração dos regimes soberano e disciplinar, a somatopolítica neoliberal promove uma pilhagem neurológica sem precedentes, recortando e usurpando nossas últimas forças vitais que restaram após a espoliação do capitalismo escravocrata e industrial. Sua estratégia é disponibilizar modelos de subjetividade e corporalidade préfabricados perfeitamente adaptados à sociedade do consumo, moldando preventivamente grande parte dos nossos modos, individuais e coletivos, de pensar, sentir e agir. Corpo ocidental, portanto, é o termo propositalmente impreciso que utilizamos aqui para tentar designar esse conjunto imensamente diverso de corpos sujeitados à fase globalizada do capitalismo, cujos comportamentos, gestos e desejos, apesar das especificidades (regionais, culturais ou fenotípicas) de cada povo, são mais ou menos parecidos porque enfrentam processos semelhantes de desencantamento, disciplinamento e esgotamento.

Seja fracassado, seja realizado, o empreendedor de si estará sempre embotado. Na atual sociedade do desempenho, não há férias que possam restaurar o cansaço coletivo porque nossa fadiga não é apenas muscular. Nossos corpos individuais estão soterrados por diferentes discursos, práticas e instituições que, há pelo menos cinco séculos, trabalham com afinco para nos manterem esgotados, disciplinados e desencantados. Assim, a somatopolítica neoliberal está abrindo um deserto existencial que deixa cada vez mais explícita nossa vulnerabilidade e desamparo perante as injunções maquínicas do capitalismo pósindustrial.

Quem fracassa na sociedade neoliberal de desempenho, em vez de questionar a sociedade ou o sistema, considera a si mesmo como responsável e se envergonha por isso. Aí está a inteligência peculiar do regime neoliberal: não permite que emerja qualquer resistência ao sistema. No regime de exploração imposta por outros, ao contrário, é possível que os explorados se solidarizem e juntos se ergam contra o

17 Talvez essa seja uma das justificativas possíveis para a relevância que a chamada saúde mental vem ganhando no debate público nas últimas décadas: pela primeira vez, as pessoas brancas euro-americanas estão sentindo no próprio corpo os efeitos de uma devastação psíquica e somática resultantes da exploração maquínica-coisificadora até então reservada aos corpos das pessoas negras/racializadas e das mulheres. 
explorador. [...] Já no regime neoliberal de autoexploração, a agressão é dirigida contra nós mesmos. Ela não transforma os explorados em revolucionários, mas sim em depressivos (Han, 2018, p. 16).

Neste contexto, parece cada vez mais difícil propor um programa político ou estético capaz alinhavar as fraturas sociais e existenciais que daí derivam. Se, algumas décadas atrás, nos sentíamos impedidos de efetuar uma sociabilidade um com o outro, parece que hoje em dia o indivíduo não consegue se relacionar sequer consigo mesmo. Contudo, enfim, se o capitalismo tardio articula uma somatopolítica neoliberal que produz as corporalidades e as subjetividades sobre os quais operará e pelas quais será operado, é possível uma insurreição justamente a partir do próprio corpo, essa dimensão psicossomática visível e encarnada do neoliberalismo. Se quisermos desvirtuar o caminho que inevitavelmente já estamos trilhando, precisamos começar confrontando e reinventando nossa própria intimidade, gestualidade e coletividade, premissa essa que vem sendo crescentemente trabalhada por artistas-educa-dores.

\section{A crise da sensibilidade do corpo ocidental}

Nossa hipótese aqui é polêmica: o corpo ocidental e ocidentalizado sofre de um esgotamento, de um disciplinamento e de um desencantamento que somente a psicologia tradicional ou as grandes religiões não podem sanar. Do mesmo modo, as explicações estritamente sociológicas do sofrimento não são capazes de esgotar o tema. Nessas análises, há alguma especificidade do sofrimento contemporâneo que escapa à psicologia, à sociologia ou à religião e que somente a arte tem aptidão para deslindá-la: a crise da sensibilidade.

O indivíduo do século XXI sofre não apenas por influxos do inconsciente (psicanálise), por desorientação moral (religião), por carência material (economia) ou por violação de direitos (justiça). O sofrimento empreendido pela somatopolítica neoliberal (que muitas vezes se confunde com prazer) está também assentado em um "[...] imenso vazio na subjetividade que tende a se tornar cada vez mais absurda e sem recursos" (Guattari, 2012, p. 30).

Ao mesmo tempo, o corpo ocidental vem sendo destituído dos saberes e das 
tecnologias somáticas mais "vernaculares" da espécie humana. Costumamos pensar que nosso equilíbrio físico, mental, emocional ou "energético" começou a ser perturbado apenas pela modernidade, com seus ruídos e velocidades inumanos. Mas, se observarmos diferentes povos originários, perceberemos um conjunto muito elaborado de medicinas (danças, plantas, cantos, chás, defumações, rituais, meditações etc.) utilizadas regularmente para restaurar esse delicado equilíbrio corpo-mente-espírito e também indivíduo-sociedade.

Há um poder sobrenatural, que todo ser humano tem, que não pode ser cultivado pela leitura ou escrita. Precisamos fazer alguma coisa com nossos corpos físicos e com os elementos naturais da terra: fogo, água, ar, minerais e madeira. As cerimônias nativas norte-americanas, algumas das quais muito antigas, e muitas das sociedades secretas que os índios têm, estão baseadas nesta intenção: fazer a conexão de novo, e de novo, e de novo, com a terra. Quando nos mantemos conectados com a terra, podemos manter nosso poder. Achamos a vida vazia e insatisfatória ou sem inspiração porque não fazemos cerimônias o suficiente (Rael [Bela Flecha Pintada ou Tsluu teh koy ay], 2017, p. 14).

Com isso, afirmamos que os diagnósticos e os prognósticos acerca do malestar físico, mental e emocional mais contemporâneos precisam considerar também a dimensão da sensibilidade/sensorialidade (experiência estética) e da sociabilidade (ritual, comunhão, cerimônia, relação) fragilizadas no contexto neoliberal, para além dos fatores psicológicos, sociológicos, jurídicos ou religiosos. Se cada forma de viver implica formas específicas de sofrer, para enfrentar as dores e os sofrimentos impingidos pela somatopolítica neoliberal, precisamos considerar a crise da sensibilidade que nossos corpos e subjetividades estão atravessando neste contexto.

Por crise da sensibilidade entendemos o conjunto de forças acionadas pela somatopolítica neoliberal para dar manutenção à servidão voluntária e maquínica em escala global. Supomos aqui que a ordem neoliberal continua em expansão porque, em algum grau, con-sentimos sensorialmente - por ignorância, negligência ou conveniência - com os ditames do capitalismo. Tal consentimento é simultaneamente causa e efeito de forças em contínua ação na escala micropolítica do corpo individual. Dentre as muitas forças, destacamos aqui 
apenas três delas:

(1) o sedentarismo compulsório: a somatopolítica neoliberal é causa e efeito de um corpo sedentário cada vez mais sentado. Etimologicamente, sentar e sedar derivam da mesma palavra-mãe latina sedere (Bailtello Jr., 2017, p. 21). Para operar as incontáveis máquinas industriais e digitais, é necessário que o impulso vital do movimento seja sedado no corpo do indivíduo (sobretudo nos anos escolares). Assim, a postura sentada facilita a automação em escala global, porque funciona perfeitamente para atrofiar os músculos e hipertrofiar a mente, operação fundamental para suportar os atuais modos de produção-consumo.

Sendo a vida sedentária o estágio civilizatório desejado e alcançado pela sociedade contemporânea, pela cultura racional, letrada e escolarizada, o que se plasma com ela é o decréscimo da mobilidade, não apenas do corpo, mas também do pensar, de sua imprevisibilidade, de sua sempre ativa criatividade e de sua capacidade de ... surpreender. Com a postura sentada pretende-se acalmar o animal inquieto e criativo, um verdadeiro vulcão pronto para entrar em erupção a qualquer momento. Com a ação de sentar acredita-se ter domado o corpo e civilizado o homem. Parece que tudo no mundo moderno [...] gira em torno de uma cadeira, um sofá, uma poltrona, um trono, um assento, um banco (de sentar), uma banqueta. Sentar-se tornou-se sinônimo de conforto. E a tecnologia contemporânea investiu todas as suas fichas em aparelhos que são operados por pessoas sentadas (Bailtello Jr., 2017, p. 18).

(2) a privação sensorial: a somatopolítica neoliberal é causa e efeito de um corpo carente cada vez mais privado de experiências sensoriais. A cultura globalizada privilegia os sentidos de distância (visão e audição) enquanto interdita os sentidos de proximidade (paladar, olfato e, sobretudo, tato). Se os sentidos nos informam o que se passa no "exterior", em contrapartida, os sentidos também nos informam o que se passa no "interior". Carentes de experiências de toque que provoquem a propriocepção, nossos corpos desconhecem a própria intimidade. Assim, experienciamos um re-conhecer-se no mundo a partir daquilo que apenas podemos ver e mostrar: as imagens.

A impessoalidade da vida no mundo ocidental chegou a tal ponto que, enfim, produzimos uma raça de intocáveis. [...] Em razão de nossa progressiva sofisticação e falta de envolvimento recíproco, passamos a utilizar exageradamente a comunicação verbal, chegando inclusive a 
virtualmente excluir de nossa experiência o universo da comunicação não-verbal, para nosso acentuado empobrecimento. A linguagem dos sentidos, na qual podemos ser todos socializados, é capaz de ampliar nossa valorização do outro e do mundo em que vivemos, e de aprofundar nossa compreensão em relação a eles. Tocar é a principal dessas outras linguagens. As comunicações que transmitimos por meio do toque constituem o mais poderoso meio de criar relacionamentos humanos, como fundamento da experiência (Montagu, 1988, p. 19, grifo nosso).

(3) a supremacia da extroversão: ${ }^{18}$ a somatopolítica neoliberal é causa e efeito de um corpo distraído cada vez mais extrovertido. Com a digitalização do cotidiano, é necessário que nossa atenção esteja constantemente disponível para produzir e consumir. Não há mais distinção entre trabalhar e descansar, dia útil e final de semana, dia e noite. A cultura globalizada de ritmo 24/7 pressupõe a supremacia de uma dinâmica extrovertida, em que as práticas de introspecção/contemplação, o ócio e o próprio sono são controlados e mercantilizados. Neste sentido, nossa insônia global (bem como a depressão, a crise de ansiedade, a síndrome de burnout, entre outros sintomas de esgotamento) é um distúrbio imediatamente convertido em mercadoria.

O dr. Eric Schmidt [então diretor da empresa multinacional de serviços on-line e software dos Estados Unidos chamada Google] declarou que o século XXI seria sinônimo do que chamou de "economia da atenção", e que as corporações globais dominantes seriam aquelas que lograssem mobilizar e captar o maior número de "globos oculares". A intensidade da competição diária por acesso às horas de vigília de um indivíduo e o controle delas é resultado da enorme desproporção entre os limites humanos, temporais, e a quase infinita quantidade de "conteúdo" à venda. Mas o sucesso corporativo também será aferido pela quantidade de informação que pode ser extraída, acumulada e utilizada para prever e modificar o comportamento de qualquer indivíduo com identidade digital. Um dos objetivos de empresas como o Google, o Facebook e outras (daqui a cinco anos, os nomes podem ser outros) é normalizar e tornar indispensável, como esboçou Deleuze, a ideia de uma interface contínua [...], uma ocupação relativamente ininterrupta com telas iluminadas de diversos tipos, que exigem constante interesse ou resposta. É claro que há interrupções, mas não são intervalos nos quais seja possível alimentar e apoiar qualquer tipo de contraprojeto ou linha de pensamento (Crary, 2016, p. 84-85).

\footnotetext{
18 O termo supremacia da extroversão (extrovert supremacy) foi originalmente cunhado pelo artista, curador e ativista Hamja Ahsan em seu livro Shy radicals: the antisystemic politics of the militant introvert (em tradução livre, Radicalmente tímidos: a política anti-sistêmica do militante introvertido). Emprestamos seu termo para dar-lhe outro significado.
} 
Haveria muitas outras forças somatopolíticas neoliberais responsáveis pela crise da sensibilidade que poderiam ser aqui descritas. ${ }^{19}$ Apesar das especificidades nos modos de viver e sofrer de cada contexto (região, geração etc.), supomos que várias dessas forças incidem semelhantemente em escala global, tais quais as anteriormente descritas. Isso nos inclina a sugerir que sua condição universal pode servir a um diagnóstico e a um prognóstico mais sensível da realidade somatopolítica neoliberal operante em cada indivíduo.

Com isso, na ambição de imaginarmos formas universais de desalienação do corpo (Safatle, Silva Jr., Dunker, 2019, p. 81), sugerimos que uma possível terapêutica experimental universal precisará ser capaz de deslindar a crise da sensibilidade que é simultaneamente causa e efeito da nossa servidão voluntária e maquínica. Se concordarmos que os atuais modos compulsórios de sofrer estão intimamente relacionados aos modos de viver neoliberais, ${ }^{20}$ então o gesto artístico-educativo-terapêutico necessitará, direta ou indiretamente, proporcionar experiências capazes de reencantar, desautomatizar e descansar o corpo ocidental, ainda que temporariamente, experimentação essa crescentemente realizada por artistas-educa-dores.

\section{Conclusão: artista-educa-dor}

Invocamos aqui o neologismo artista-educa-dor ${ }^{21}$ como uma das figuras que tem nos auxiliado, individual e coletivamente, a perceber, lidar, narrar, enfrentar

19 Tais como a solidão hiperconectada, o paroxismo da visibilidade, o individualismo programado, a hiperestesia erótica etc. Uma vez que há um padrão coletivo que se repete no nosso comportamento individual (gestos, desejos, consumos etc.), produzido e naturalizado pela somatopolítica neoliberal, é possível que qualquer pessoa subalternizada pelo neoliberalismo identifique, revele e nomeie tais forças por meio de uma minuciosa (auto)etnografia sensorial (Eugenio, 2019, p. 38) do seu próprio cotidiano.

${ }^{20}$ Alicerçados, conforme demonstrado, no desencantamento, no disciplinamento e no esgotamento do corpo ocidental, assegurados pelo sedentarismo compulsório, pela privação sensorial e pela supremacia da extroversão da somatopolítica neoliberal.

${ }^{21}$ Reconhecemos aqui que o termo artista-educa-dor possui limitações no tocante a seu efeito funcionar exclusivamente com o uso no masculino (educa-dor), reproduzindo subalternizações e silenciamentos (no âmbito da linguagem) aos quais o próprio neologismo e o artigo explicitamente se opõem. No plural, o termo torna-se mais inclusivo/neutro (artistas-educa-dores), o que não acontece no singular, reforçando assim o falso sujeito universal masculino. Ainda assim, optamos por manter esse termo porque não encontramos tal efeito na flexão de gênero no feminino (artista-educa-dora) ou com outras palavras de conotação semelhante. Reforçamos também que tal termo não tem qualquer pretensão de cunhar um novo conceito, mas tão somente deslocar um sufixo para ampliar a leitura de artistas-educadores sobre a própria práxis artístico-pedagógico-terapêutica. 
ou inclusive tratar as dores, os sofrimentos e os mal-estares específicos da nossa época. Embora o sufixo dor, quando apenas separado da palavra educa-dor, não remeta etimologicamente à experiência sensorial desagradável/angustiante (dor), sugerimos realizar esse simples deslocamento para destacarmos que, no contexto de uma educação (do) sensível (cf. Duarte Jr., 2010), artistas-educa-dores que se dispuserem a deslindar a crise da sensibilidade dos corpos no século XXI, invariavelmente, atravessarão a temática do sofrimento.

Dado que ainda dispomos de alguma autonomia na escala micropolítica do próprio corpo, aventamos que as experiências artístico-pedagógicas que estão cruzando arte-saúde-espiritualidade, tais como as citadas na introdução e outras, têm o poder de reencantar, desautomatizar ou descansar o corpo ocidental por meio da reapropriação, ainda que ínfima e temporária, da vitalidade, da expressividade, da coletividade e da liberdade das nossas existências constantemente capturadas pelos mecanismos de controle e exploração neoliberais.

Independentemente do repertório cultural/filosófico/espiritual (yoga, chi kung, budismo, taoísmo, umbanda, candomblé, xamanismo etc.) cruzado com arte e saúde, tais projetos possibilitam a experimentação de outros saberes e epistemologias corporais divergentes daquela disponibilizada pela somatopolítica neoliberal. Assim, a vivência sensorial de outras cosmologias, usos e representações não-ocidentais do corpo têm, potencialmente, a capacidade de abrir nossa imaginação para reinventarmos nossa intimidade e nossa gestualidade ora operantes. Não se trata de voltar atrás, resgatar ou recuperar um estado normal anteriormente perdido, mas de recriar o ponto nevrálgico, conforme demonstrado, do capitalismo: a relação corpo-subjetividade. Por isso, "[n]ão é inteligência, nem tecnologia, nem tampouco ciência que nos falta, mas a criação de novos possíveis e a criação de novos desejos” (Lazzarato, 2017, p. 193).

Deste modo, o termo artista-educa-dor não possui qualquer pretensão de que artistas-educadores sejam capazes de educar a dor alheia (afinal, tem sido difícil cuidar inclusive da própria dor), mas que os espaços artístico-pedagógicosterapêuticos, propiciados por artista-educa-dores e compartilhados com outros 
participantes, podem funcionar como "[...] catalisadores de bifurcações existenciais" (Guattari, 2012, p. 39), isto é, podem abrir novas percepções sensoriais e conceituais acerca da própria existência, individual e coletiva, para além daquelas já cristalizadas.

Uma imensa reconstrução das engrenagens sociais é necessária para fazer face aos destroços [corporais e subjetivos] do CMI [capitalismo mundial integrado]. Só que essa reconstrução passa menos por reformas de cúpula, leis, decretos, programas burocráticos do que pela promoção de práticas inovadoras, pela disseminação de experiências alternativas, centradas no respeito à singularidade e no trabalho permanente de produção da subjetividade [e da corporalidade], que vai adquirindo autonomia e ao mesmo tempo se articulando ao resto da sociedade (Guattari, 2012, p. 44, grifos nossos).

Em outras palavras, estimamos aqui que tais projetos e experiências, de diferentes maneiras, oferecem a possibilidade de “[...] reinventar a relação do sujeito com o corpo, com o fantasma, com o tempo que passa, com os 'mistérios' da vida e da morte" (Guattari, 2012, p. 16) por meio de "[n]ovas apreensões 'prépessoais' do tempo, do corpo, do sexo..." (Guattari, 2012, p. 54), da política, da cidade, do trabalho, enfim, de todas concreções existenciais que nos constituem enquanto indivíduo e sociedade. Reinventar a intimidade e a gestualidade, portanto, consiste em expressar e transformar a performance que realizamos diariamente para sustentar nossa ficção somatopolítica.

\begin{abstract}
A performance como reterritorialização na terra fértil dos possíveis, como resposta à urgência de cuidar de si, do outro e do planeta, como estética emergente e urgente de um mundo globalizado. A performance como ritual de comunhão, como convite para a partilha, o sossego, a troca. Em outras palavras: aqui, agora, dentro de um movimento compartilhado entre artista e participante, a performance como o mais perfeito estado de entrega ao mundo (Alice, 2016, p. 34, grifo nosso).
\end{abstract}

Não à toa, a palavra cura é utilizada, muitas vezes, para tentar caracterizar a experiência sensorial e conceitual vivenciadas por participantes e proponentes nesses encontros. Sugerimos interpretar o termo cura, no entanto, não no sentido determinista de uma resolução derradeira da dor ou do sofrimento, tampouco no aspecto espontâneo da chamada autoajuda, mas cura no sentido do tratamento 
demorado e apurado que se dá, por exemplo, à madeira, ao queijo ou ao concreto. Curar no sentido de preparar, aparelhar, laborar, maturar.

Dito tudo isso, concluímos este artigo reconhecendo e valorizando o crescente cruzamento arte-saúde-espiritualidade realizado por diferentes artistas-educa-dores que estão criando espaços e metodologias (cria-dores) para elaborarmos (narra-dores) e compartilharmos ferramentas conceituais e sensoriais capazes de curar (cura-dores) as dores e sofrimentos decorrentes da somatopolítica neoliberal: curar, no sentido psicanalítico, enquanto exercício da pulsão (Schiavon, 2019, p. 307); curar, no sentido somático, enquanto exercício da vitalidade; curar, no sentido ancestral, enquanto exercício da memória; curar, no sentido jurídico, enquanto exercício da justiça; curar, no sentido sociológico, enquanto exercício da coletividade; curar, no sentido afetivo, enquanto exercício da alteridade; curar, no sentido ético, enquanto exercício da responsabilidade; curar, no sentido micropolítico, enquanto exercício da expressividade; curar, no sentido macropolítico, enquanto exercício da liberdade; curar, no sentido epistêmico, enquanto exercício da incerteza; curar, no sentido poético, enquanto exercício do impossível; em suma, curar, no sentido performático, enquanto exercício da coragem necessária para entregar-se ao mundo.

\section{Referências}

ALICE, Tania. Performance como revolução dos afetos. São Paulo: Annablume, 2016.

BAITELLO JUNIOR, Norval. O pensamento sentado: sobre glúteos, cadeiras e imagens. São Leopoldo-RS: Ed. Unisinos, 2017.

BISHOP, Claire. Trad. Milena Durante. Antagonismo e estética relacional. Revista Tatuí. Recife, n. 12, p. 109-132, 2012. Disponível em: http://www.revistatatui.com.br/wp/wp-content/uploads/2011/10/revista-tatui12.pdf. Acesso em: 28 dez. 2020.

BORRIAUD, Nicolas. Trad. Denise Bottmann. Estética relacional. São Paulo: Martins, 2009. 
BROWN, Wendy. Trad. Mario A. Marino, Eduardo Altheman C. Santos. Nas ruínas do neoliberalismo: a ascensão da política antidemocrática no ocidente. São Paulo: Editora Filosófica Politeia, 2019.

CRARY, Jonathan. Trad. Joaquim Toledo Jr. 24/7: capitalismo tardio e os fins do sono. São Paulo: Ubu Editora, 2016.

DELEUZE, Gilles. Trad. Ovídio de Abreu, Roberto Machado. Sobre o teatro: Um manifesto de menos / O esgotado. Rio de Janeiro: Ed. Zahar, 2010.

DUARTE JR., João-Francisco. O sentido dos sentidos: a educação (do) sensível. Curitiba: Criar edições, 2010.

DUNKER, Christian. Reinvenção da intimidade: políticas do sofrimento cotidiano. São Paulo: Ubu Editora, 2017.

EUGÊNIO, Fernanda. Caixa-livro AND. Rio de Janeiro: Fada inflada, 2019. V. Caderno de cor rosa.

FABRINNI, Ricardo. Fronteiras entre arte e vida. ArteFilosofia, Ouro Preto, v. 9, n. 17, p. 41-60, 2014. Disponivel em: https://periodicos.ufop.br:8082/pp/index.php/raf/article/view/506. Acesso em: 17 dez. 2020.

FEDERICI, Silvia. Trad. Coletivo Sycorax. Calibã e a bruxa: mulheres, corpo e acumulação primitiva. São Paulo: Ed. Elefante, 2017.

FEDERICI, Silvia. Trad. Coletivo Sycorax. O ponto zero da revolução: trabalho doméstico, reprodução e luta feminista. São Paulo: Ed. Elefante, 2019.

FOUCAULT, Michel. Trad. Raquel Ramalhete. Vigiar e punir. nascimento da prisão. Petrópolis-RJ: Vozes, 2013.

GUATTARI, Félix. Trad. Maria Cristina F. Bittencourt. As três ecologias. CampinasSP: Papirus, 2012.

HAN, Byung-Chul. Trad. Enio Paulo Gianchini. Sociedade do cansaço. PetrópolisRJ: Vozes, 2017.

HAN, Byung-Chul. Trad. Maurício Liesen. Psicopolítica: o neoliberalismo e as novas técnicas de poder. Belo Horizonte: Ed. Âyiné, 2018.

LAPOUJADE, Davi. O corpo que não aguenta mais. In: GADELHA, Sylvio (org.). Nietzsche e Deleuze: que pode o corpo. Rio de Janeiro: Relumé Dumará, Fortaleza: Secretaria da Cultura e Desporto, 2002. 
LAZZARATO, Maurizio. Trad. Daniel P. P. da Costa. O governo do homem endividado. São Paulo: n-1 edições, 2017.

LAZZARATO, Maurizio. Trad. Paulo Domenech Oneto. Signos, máquinas e subjetividades. São Paulo: Edições Sesc São Paulo: n-1 edições, 2014.

MBEMBE, Achille. Trad. Sebastião Nascimento. Crítica da razão negra. São Paulo: n-1 edições, 2018.

MONTAGU, Ashley. Trad. Maria Sílvia Mourão Netto. Tocar. o significado humano da pele. São Paulo: Summus, 1988.

PRECIADO, Paul B. Trad. Maria Paula Gurgel Ribeiro. Texto Junkie: sexo, drogas e biopolítica na era farmacopornográfica. São Paulo: n-1 edições, 2018.

RAEL, Joseph [Bela Flecha Pintada ou Tsluu teh koy ay]. Trad. Vera de Andrada e Silva. Cerimônias do espírito vivo. São Paulo: Polar, 2017.

SAFATLE, Vladimir; SILVA JR., Nelson da; DUNKER, Christian (Orgs.). Patologias do social: arqueologias do sofrimento psíquico. Belo Horizonte: Autêntica editora, 2019.

SCHIAVON, João Perci. Pragmatismo pulsional: clínica psicanalítica. São Paulo: n-1 edições, 2019. 